\title{
USUAL ERRATIC PHENOMENON AND DRAMATIC OUTCOME A CASE REPORT OF PHENYTOIN TOXICITY
}

Ketan L. Pakhale ${ }^{1}$, Archana Bhate ${ }^{2}$

\section{HOW TO CITE THIS ARTICLE:}

Ketan L. Pakhale, Archana Bhate. "Usual Erratic Phenomenon and Dramatic Outcome a Case Report of Phenytoin Toxicity". Journal of Evolution of Medical and Dental Sciences 2014; Vol. 3, Issue 65, November 27; Page: $14221-14223$, DOI: $10.14260 /$ jemds/2014/3905

ABSTRACT: Phenytoin is still one of the most commonly used antiepileptic drugs in clinical practice around the globe. It has a range of familiar prejudicious and side effects, which have been reported formerly including ataxia, dizziness, visual disturbance, nystagmus, diplopia and cognitive dysfunctions amongst others. Here we are reporting a rare case of phenytoin toxicity presenting dramatically as a behavioural disorder resulting from underlying primary adverse effects of phenytoin, which were clinically overlooked. Discontinuation of phenytoin resulted in remission of side effects as well as the secondary behavioural manifestations.

KEYWORDS: phenytoin toxicity, miscommunication, dramatic presentation, mislead, careful history taking.

INTRODUCTION: Phenytoin seems to be the most commonly used and studied antiepileptic agent and its side effects and toxicity symptoms are well documented.(1) It is a well-known fact that phenytoin may commonly cause central nervous system side effects like sedation, blurring of vision, nystagmus, ataxia, hyperkinesia, psychosis and phenytoin encephalopathy. Research has shown that neurological and cognitive adverse effects are more common and more deleterious with phenytoin and other older antiepileptic drugs than with the newer antiepileptic. $(1,2,3)$

Moreover these usual erratic neurological and cognitive adverse effects can be more troublesome in young, physically active cases and those patients with active cognitive lifestyles, resulting in a variety of problems ranging from poor performance in studies to impairment in the work place.

Furthermore these side effects if overlooked, which is rather common as has been reported earlier,(4) can lead to behavioural changes ranging from irritability and low mood to suicidality especially in patients with active cognitive lifestyles including school-aged children and adolescents. We are reporting a rare case of phenytoin toxicity in a 16 year old male presenting dramatically as poor scholastic performance with behavioural changes.

CASE REPORT: A 16 year old male patient, student of the $10^{\text {th }}$ class was accompanied by his mother presented with vomiting, fever, giddiness, abnormal behaviour. These spells were associated with irritability, feeling low along with death wishes. On inquiry patient had been diagnosed with GTCS since $2 \& 1 / 2$ years and was on phenytoin $300 \mathrm{mg} /$ day. However two recent episodes, phenytoin had been changed to Phenytoin ER. But due to "miscommunication" patient continued on old along with the new drug.

He started falling back in his studies and hence performed very poorly in examinations to the extent that in one paper he wrote nothing because of the blurred vision and difficulty maintaining balance while walking. The treating physician and family members linked these symptoms to 


\section{CASE REPORT}

academic performance anxiety due to the dramatic presentation and episodic nature of the symptoms.

- Patient's Vitals were normal.

- Phenytoin level $38 \mathrm{ug} / \mathrm{ml}$.

- Patient was diagnosed as Phenytoin toxicity on basis of phenytoin levels.

- The patient was advised to discontinue phenytoin \& was started on other antiepileptic drugs.

DISCUSSION: The initial presentation of this case was indeed dramatic in nature and hence the treating physicians were misled into considering the possibility of stress induced psychiatric disorders or aggravation of the underlying seizure disorder. However careful history taking and supporting scientific evidence ruled out such disorders.

Hence, this case report serves to alert clinicians to remain clinically vigilant for such manifestation in patients with active cognitive lifestyles who are on long term phenytoin therapy. Caution needs to be exercised when making dosage changes as we saw that even a small change can precipitate or mitigate the side effects. There is a need for imagination the erratic association of serum levels and toxic effects especially in case of phenytoin so that the progression to such possibly hazardous behavioural changes and the dramatic consequences thereof can be prevented.

\section{CONCLUSION:}

- A thorough patient's history should be obtained.

- There is a need of awareness between the clinicians to be vigilant for patients who are on phenytoin treatment.

- We should keep in mind to check serum phenytoin levels of patients who are on phenytoin treatment on regular interval time.

\section{REFERENCES:}

1. Livanaine. M, Savolainen H. Side effects of phenobarbital and phenytoin during long-term treatment of epilepsy. Acta Neurol Scand Suppl 1983; 97: 49-67.

2. Larsen.JR, Larsen LS. Clinical features and management of poisoning due to phenytoin. Med Toxicol Adverse Drug Exp 1989; 4 (4): 229-45.

3. Cohen AF, Ashby L, Crowley D, Land G, Peck AW, Miller AA. Lamotrigine (BW430C), a potential anticonvulsant. Effects on the central nervous system in comparison with phenytoin and diazepam. Br J Clin Pharmacol 1985; 20 (6): 619-29.

4. Hwang WJ, Tsai JJ. Acute phenytoin intoxication: causes, symptoms, misdiagnoses, and outcomes. Kaohsiung J Med Sci 2004; 20 (12): 580-5.

5. Hussein A, Abdulgalil A, Omer F, Eltoum H, Hamad A, El-Adil O, et al. Correlation between Serum Level of Antiepileptic Drugs and their Side Effects. Oman Med J 2010; 25 (1): 17-21. 


\section{CASE REPORT}

\section{AUTHORS:}

1. Ketan L. Pakhale

2. Archana Bhate

\section{PARTICULARS OF CONTRIBUTORS:}

1. Second Year Resident, Department of Medicine, D. Y. Patil University, School of Medicine Hospital \& Research Centre, Navi Mumbai.

2. HOD \& Professor, Department of Medicine, D. Y. Patil University, School of Medicine Hospital \& Research Centre, Navi Mumbai.

\section{NAME ADDRESS EMAIL ID OF THE} CORRESPONDING AUTHOR:

Dr. Ketan L. Pakhale, Flat No. 407,

Harsha Apartment, Amrut Nagar, Ghatkopar (W), Mumbai-400086.

Email: drketan.pakhale@gmail.com

Date of Submission: 07/11/2014. Date of Peer Review: 08/11/2014. Date of Acceptance: 21/11/2014. Date of Publishing: 27/11/2014. 